\title{
Planejamento do turismo de base comunitária: perspectivas críticas
}

Planning of a community-based tourism: critical perspectives Planificación del turismo de base comunitária: perspectivas críticas http://dx.doi.org/10.18472/cvt.17n3.2017.1161

Fabiana A. Bernardes Almeida 〈 fabiana.a.b.almeida@gmail.com > Universidade Federal de Minas Gerais (UFMG), Belo Horizonte, MG, Brasil

Julia Fonseca de Castro〈juliafcastro@gmail.com >

Universidade Federal de Minas Gerais (UFMG), Belo Horizonte, MG, Brasil

CRONOLOGIA DO PROCESSO EDITORIAL

Recebimento do artigo: 03-nov-2015

Aceite: 16-out-2017

FORMATO PARA CITAÇÃO DESTE ARTIGO

ALMEIDA, F. A. B.; CASTRO, J. F. de. Planejamento do turismo de base comunitária: perspectivas críticas. Caderno Virtual de Turismo. Rio de Janeiro, v. 17, n. 3, p. 66-81, dez. 2017.

REALIZAÇÃO

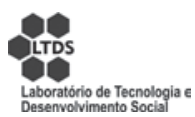

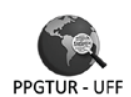

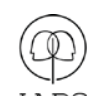

APOIO INSTITUCIONAL

COPPE

UFR]

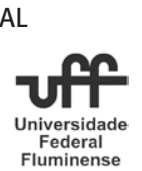

EDIÇÃO

PATROCÍNIO

IRTITR
Q6)FAPER 


\section{RESUMO}

O presente artigo apresenta reflexões críticas acerca do planejamento do turismo de base comunitária, a partir do debate teórico dos conceitos, aplicações e sentidos do planejamento no Brasil. Para tanto, parte de algumas questões norteadoras, a saber: Quais os sentidos da participação social? Quais conhecimentossaberes se espera construir com o planejamento do turismo com as (e pelas) comunidades? Qual o papel do bacharel em turismo no planejamento do turismo de base comunitária? Acredita-se que a acepção do planejamento do turismo de base comunitária no Brasil necessita ser debatida à luz da teoria da participação social, do desenvolvimento comunitário, assim como do planejamento participativo. Essas perspectivas permitem maior clareza e leitura crítica dos processos de intervenção nos territórios ditos comunitários, o que suscita a reflexão dos limites e potencialidades da conotação da participação social. O que se pode pensar é que a política pública de turismo não legitima os sentidos genuínos da participação social. O debate teórico encaminha argumentos sobre os riscos da reprodução da lógica convencional em contextos comunitários e que incentive a autonomia nas chamadas comunidades.

Palavras-chave: Participação social. Desenvolvimento comunitário. Planejamento do turismo de base comunitária.

\section{ABSTRACT}

This article presents critical reflections about the planning of communitarian context tourism, starting on the theoretical debate about the concepts, applications and meanings of planning in Brazil. For this, part of some guidance questions, namely: which are the meanings of social participation? Which knowledges one waits set up with the planning of tourism with and by communities? How is the role of a tourism graduate on the planning in a community-based tourism? We believe that the sense of planning of a communitybased tourism in Brazil needs to be discussed on the light of social participation theory, of communitarian development, as well as of participative planning. These perspectives allow more clarity and critical lecture about the interventional processes in the territories so-called community, which lead us to the reflection of the limits and potentialities of the connotation of the social participation. What we can think is that the public polices of tourism did not legitimates the genuine senses of a social participation. The theoretical discussion refers arguments about the risks to copy the formal logic in communitarian contexts and that encourage the autonomy in the so-called communities.

Keywords: Social participation. Communitarian development. Community-based tourism planning.

\section{RESUMEN}

El siguiente artículo presenta reflexiones críticas sobre la planificación del turismo de base comunitaria, a partir del debate teórico de los conceptos, aplicaciones y sentidos de la planificación en Brasil. Para esto, el punto de partida es analizar cuestiones orientadoras, a saber: ¿cuáles son los sentidos de la participación social? ¿Cuáles conocimientos-saberes se espera construir con la planificación del turismo con y por las comunidades? ¿Cuál es el rol del profesional de turismo en la planificación del turismo de base comunitaria? Se cree que la acepción de la planificación del turismo de base comunitaria en Brasil necesita ser debatida a partir de la teoría de la participación social, del desarrollo comunitario, así como de la planificación participativa. Estas perspectivas permiten lecturas críticas sobre los procesos de intervención en los territorios denominados comunitarios, lo que suscita la reflexión de los límites y potencialidades de la connotación de la participación social. Lo que se puede pensar es que la política pública de turismo no legitima los sentidos genuinos de la participación social. El debate teórico plantea argumentos sobre los riesgos de la reproducción de la lógica convencional en contextos comunitarios y que incentiven la autonomía en las llamadas comunidades.

Palavras clave: Participación social. Desarrollo comunitario. Planificación del turismo de base comunitaria. 


\section{INTRODUÇÃO}

Entre os diversos caminhos possíveis para a reflexão acerca do planejamento do turismo de base comunitária no Brasil, é frequente a opção por estudos de caso que ampliam o debate contemporâneo e cujos resultados podem ser, inclusive, aplicados em curto prazo. É importante, todavia, considerar que os debates baseados em casos e projetos não suprem a necessidade de reflexões críticas que sejam abrangentes com relação aos conceitos, aos discursos e consequentes práticas adotadas pelos atores envolvidos com o turismo em suas diversas escalas.

A proposta do presente artigo é debater a relação entre planejamento do turismo de base comunitária, participação social, desenvolvimento comunitário, planejamento participativo e políticas públicas de turismo no Brasil, por meio de um olhar que investigue os rastros de criação e de apropriação do conceito de planejamento, de participação social e, também, dos conceitos relacionados ao desenvolvimento comunitário e autonomia em discursos diversos. Busca-se o histórico e os usos institucionais de tais conceitos de modo a refletir sobre os sentidos atribuídos a eles e, sobretudo, para pensar nos deslocamentos de sentido e no próprio esvaziamento de significado de tais termos em função do uso indiscriminado e eticamente questionável.

Pretende-se neste texto criar uma discussão ampla que represente um passo de recuo, um passo atrás ou uma pausa para a reflexão, já que se observa a escassez de reflexões centradas na ambiguidade com a qual os citados conceitos são utilizados. A ênfase nas técnicas e nos mecanismos de planejamento participativo, criada para atender à demanda por soluções e estratégias replicáveis para problemas comunitários, parece sobrepor-se à necessidade de reflexão crítica acerca da natureza das questões envolvidas. A contribuição do presente artigo para a temática referente ao turismo comunitário e/ou de base comunitária consiste na leitura crítica que os sentidos envolvidos na ideia central de planejamento participativo permitem, de modo a colaborar com o entendimento aprofundado das seguintes questões: Quais os sentidos da participação social? Como o conceito de participação social se expressa no planejamento do turismo no contexto brasileiro? Quais conhecimentos-saberes se espera construir com o planejamento do turismo nas e pelas comunidades? Qual o papel do bacharel em turismo nos processos de planejamento do turismo de base comunitária?

A última pergunta é de importância fundamental, uma vez que o planejamento é um dos conteúdos que fazem parte dos pilares da formação do bacharel em turismo no País e enseja, obviamente, uma concepção geral de turismo que atribui ao Estado a instância do planejamento e ao turismólogo (profissional de turismo), como a outros profissionais, o papel de planejar o turismo em diversas instituições e contextos, inclusive em territórios tradicionais. Nesse sentido, é importante criar um momento de reflexão no que diz respeito aos conceitos de planejamento, participação social e desenvolvimento comunitário em seu aspecto histórico e contemporâneo e, além disso, das questões gerais que atravessam tais conceitos-base. O presente texto busca discutir a questão do planejamento participativo em contextos comunitários como estratégia para se pensar os modos de intervenção do turismo de base comunitária no Brasil.

\section{METODOLOGIA}

Em um texto de natureza teórica, crítica e reflexiva, os recursos utilizados são alicerçados em uma compreensão de ciência-saber e, consequentemente, de teoria, método e metodologia, distanciada de abordagens positivistas ou neopositivistas (HISSA, 2013). Em casos em que a expectativa de contribuição 
de um artigo científico estiver direcionada à publicação de dados e de resultados quantitativos ou mesmo de análises que categorizem estudos de caso - de modo a demonstrar empiricamente a aplicação de métodos e de técnicas com resultados aparentemente palpáveis - as abordagens críticas parecerão desnecessárias ou, ao menos, deslocadas.

Compreende-se, contudo, que o método utilizado neste artigo consiste em um exercício de interpretação que segue os preceitos dos estudos críticos do turismo (NECHAR; NETTO, 2010), a partir dos questionamentos construídos como exercícios de autorreflexão das autoras e das possíveis respostas ou leituras apresentadas no decorrer do texto. Reforça-se a importância do conhecimento científico a estimular, nos diversos sujeitos e atores sociais, a capacidade de articulação de ideias e de criação de interpretações acerca dos diversos contextos, de modo a promover maior compreensão sobre os desafios a serem superados. No caso do turismo de base comunitária no Brasil, a visão crítica acerca dos sentidos relacionados ao ato de se planejar e de participar do processo de planejamento é necessária para a compreensão dos limites e das possibilidades da atuação conjunta de comunidades, governos, técnicos e estudiosos.

Dessa forma, a metodologia utilizada compreende a exploração de conceitos-chave abordados em relação às bases discursivas que remontam décadas passadas e contextos globais. Estudar os fundamentos do conceito de planejamento e de participação social é a primeira etapa empreendida. Em seguida, o esforço consiste em relacionar os discursos históricos sobre planejamento estatal à realidade brasileira por meio da concatenação entre os pressupostos do planejamento e o histórico das políticas públicas de turismo. A inter-relação entre o sentido do planejamento do turismo no Brasil e os sentidos da participação social e do desenvolvimento comunitário é também discutida de modo a proporcionar uma leitura crítica e, assim, contribuir com novas práticas. Por fim, os sentidos da relação comunitária, da autonomia e da proximidade são pensados junto à lógica do planejamento do turismo de base comunitária.

\section{PLANEJAMENTO ESTATAL E SUA RELAÇÃO COM A PARTICIPAÇÃO SOCIAL NAS POLÍTICAS PÚBLICAS DE TURISMO NO BRASIL}

O estudo da trajetória do conceito de participação social revela o uso desse conceito associado, principalmente, a dois universos que envolvem a política pública: aos projetos de desenvolvimento e, principalmente, aos processos de planejamento. O que se vê nas últimas décadas no contexto da política brasileira e, em especial, nas políticas de turismo, é o uso quase obrigatório da palavra participação ou da abordagem participativa vinculada aos processos de planejamento. Se pensarmos do ponto de vista histórico, o marco formal da inserção da palavra participação nas políticas públicas se dá com a Constituição de 1988, que consagra o princípio da participação da sociedade civil (DAGNINO, 2004). É a partir da década de 1970 que, aos poucos, a ideia de participação passa a ser incorporada nos documentos das políticas públicas brasileiras. A autora supracitada afirma em sua obra que é inegável que a Constituição de 1988 é uma conquista dos movimentos sociais da década de 1980 contra o regime militar. Entretanto, é válido lembrar que nem sempre o sentido da incorporação da participação nas políticas públicas reforça o princípio da participação social como um exercício de cidadania, que envolve o cotidiano dos sujeitos e suas ações nas esferas pessoais e coletivas.

O planejamento estatal é uma função administrativa que recebe qualificações diversas: do tipo econômico, social, territorial, empresarial, pessoal, global ou setorial, além de ser caracterizado conforme o tempo de duração (curto, médio e/ou longo). Segundo Arturo Escobar (2000), o tipo de planejamento 
priorizado ao longo da segunda metade do século XX se transformou, variando do planejamento nacional -predominante durante a década de 1950 -, ao setorial e ao regional nos anos 1970, e ao local, nos anos 1980, até os dias atuais em que se destaca o do tipo sustentável e local. É importante salientar que a participação ou o princípio participativo não é considerado como um tipo de planejamento na lógica do planejamento estatal. Como se pode perceber, a participação ou o princípio participativo não é citado entre as opções ou tipos de planejamento no âmbito do Estado.

O que é planejar? Em termos administrativos, planejar é arquitetar um futuro, é criar um conjunto de ações e determinar os meios para alcançar objetivos propostos. A primeira ideia associada ao planejamento é a da criação de um plano, de um documento. Essa primeira impressão assume uma conotação negativa já que embora os planos sejam criados para servir como instrumentos para múltiplas finalidades, os objetivos políticos geralmente prevalecem, transformando os produtos do planejamento em protocolos administrativos elaborados para não "sair do papel". Contudo, para compreender o conceito de planejamento, é necessário pensar o conceito de desenvolvimento como termo polissêmico que é historicamente marcado pela ideia de evolução, maturação e pelos sentidos de mudança favorável, de etapas envolvidas entre o simples e o complexo, o inferior e o superior, o pior e o melhor (ESTEVA, 2000).

Ao considerarmos as referidas variações e abrangências, seria possível desconsiderar as dicotomias relacionadas aos termos planejamento e desenvolvimento como parte do discurso em prol da modernidade, que tem como marcos a revolução científica do século XVII, a Revolução Industrial e os avanços tecnológicos (SANTOS, 2010)? Certamente não é possível desconsiderar tal histórico associado aos termos planejamento e desenvolvimento. O planejamento apresenta uma história, carrega uma marca da cultura que o cunhou. Segundo Arturo Escobar (2000), o planejamento foi desenvolvido no contexto europeu em função do rápido crescimento urbano após a Revolução Industrial, que demandou um tipo de controle e de organização desempenhado pelo Estado. O governo tornou-se o principal agente do planejamento na resolução de problemas urbanos, principalmente de trânsito e de higiene, mas, também, de gerenciamento da população e de problemas sociais. Escobar (2000) destaca que essa "primeira organização" do contexto urbano permitiu que o planejamento fosse concebido como um grande programa, principalmente após a Segunda Guerra Mundial, que foi criado para garantir a normatização e a padronização social. Já no chamado Terceiro Mundo, o planejamento começou a ser implementado na década de 1940 por organizações internacionais como um programa de desenvolvimento.

No Brasil, como em outros países da América Latina, África e Ásia, o planejamento foi implantado junto a programas externos de desenvolvimento que eram baseados em uma concepção de história com gênese ocidental e evolucionista, além de fundamentado na ideia de que seria possível interromper o círculo vicioso de pobreza e de baixa produtividade dito como predominante em tais nações ${ }^{1}$. Arturo Escobar (2000) ressalta que o discurso a favor do planejamento como instrumento para produzir o desenvolvimento foi produzido a partir da desconsideração da própria história do colonialismo e da implantação de estruturas de dominação política e econômica empreendida durante séculos em tais territórios. O que dizer sobre os efeitos nas concepções de planejamento dos discursos ainda atuais que reforçam a visão do Brasil como pouco desenvolvido e como carente de intervenções de natureza tecnológica - apoiados no chamado progresso econômico - e desconsideram os aspectos históricos, territoriais, demográficos, geográficos e culturais?

1 De acordo com Arturo Escobar (2000), a primeira missão do Banco Mundial enviada para um país subdesenvolvido foi realizada na Colômbia, em 1949, e apresentou o objetivo de intervir na sociedade em todas as áreas para gerar o almejado desenvolvimento. 
A primeira ação de planejamento efetivamente posta em prática pelo governo brasileiro foi o Plano de Metas do governo de Juscelino Kubitscheck (1956-1961). No caso do turismo, é possível afirmar que desde esse período a atividade é compreendida como propícia ao planejamento e à intervenção estatal, já que foi promovida por meio da expansão da infraestrutura e de propagandas que visavam criar imagens positivas do País. O planejamento do turismo no Brasil se deu concomitantemente à criação de órgãos oficiais, de políticas e de seus instrumentos reguladores, como leis, decretos, decretos-lei, resoluções, portarias, alvarás, entre outros. É possível compreender a concepção padrão do planejamento do turismo no Brasil como sentido de intervenção social, ainda que o teor das políticas e ações empreendidas revelasse a ausência de uma visão abrangente e crítica da atividade, bem como em alguns períodos parecem ter sido abreviadas a ações de marketing e a ações de subsídio específico ao setor hoteleiro.

A criação da Embratur e da primeira política de turismo, em 1966, marcaram a preocupação em construir uma imagem positiva do País e em incentivar a construção de rodovias e estruturas de apoio ao setor hoteleiro, conforme destaca Cruz (2001). Na chamada década perdida de 1980, o planejamento não foi priorizado na condução da gestão estatal, inclusive em relação ao turismo que foi concebido em muitos discursos como atividade solucionadora de diversos e complexos problemas econômicos e sociais.

Um ponto crucial para discutir a concepção de planejamento turístico no discurso dos governos brasileiros trata-se da definição da atividade como solucionadora das profundas desigualdades territoriais do Brasil e para outros problemas de ordem complexa. Desde a primeira política (1966), criada na gestão presidencial do general Castelo Branco, no início da ditadura militar, a premissa do planejamento baseouse no entendimento de que o turismo apresentava a função de reduzir as desigualdades regionais e de gerar divisas, mas o descompasso entre objetivos e métodos esteve sempre presente sugerindo mais do que o superdimensionamento na capacidade de o turismo servir como instrumento para tanto, mas de descompromisso e esvaziamento ético de discursos governamentais (CRUZ, 2001).

É possível dizer muito pouco sobre a questão participativa na construção das políticas de turismo brasileiras nesse longo período citado. Se durante as décadas de 1970 e também 1980, ativistas, técnicos e pesquisadores ligados a instituições internacionais de ajuda humanitária e voltadas à promoção do desenvolvimento passaram a defender a participação popular e que os processos de planejamento estatais deveriam ser criados de "baixo para cima", pois os mesmos não estavam ganhando a força que almejavam no Brasil, o planejamento estava sendo praticado junto à criação de um arsenal de órgãos e políticas levadas a cabo pelo Estado sem ou com pouca participação popular (ESCOBAR, 2000). A discrepância de entendimento do planejamento e da participação nas políticas de turismo entre o mundo e o Brasil mostrou-se acentuada e, certamente, reflete o caminho pelo qual o turismo é concebido e fomentado no território brasileiro: com pouca participação.

Já na década de 1990, quando o País avançava rumo à abertura da economia, à privatização estatal e ao neoliberalismo, a preocupação com o planejamento voltava ao centro das atenções, exemplificada pelos diversos planos econômicos que surgiam: Plano Cruzado, Plano Bresser e Plano Verão (CRUZ, 2001). A noção de participação social também adquiria mais relevância nos discursos e políticas. A preocupação com o planejamento expressava a transição de um estado burocrático para um estado gerencial. O Brasil buscava adaptar-se a uma nova ordem mundial, e buscava a modernização, em valores que permeavam o Estado tais como: democracia, eficácia, produtividade, competitividade², e, também, participação (CRUZ, 2001). 
É importante perceber a associação da participação no planejamento estatal do turismo a partir dos anos 1990 como estratégia de transformação do modelo de gestão pública e não como uma base de apoio popular no desenvolvimento do turismo. A ambiguidade do termo participação no planejamento turístico remonta esse período, o da década de 1990, quando compõe parte da estratégia do Estado para a implementação do ajuste neoliberal e há a emergência de um projeto de Estado mínimo que se isenta progressivamente de seu papel de garantidor de direitos, por meio do encolhimento de suas responsabilidades sociais e sua transferência para a sociedade civil.

Esse projeto constitui o núcleo duro do bem conhecido processo global de adequação das sociedades ao modelo neoliberal e faz confundir o sentido de participação social no planejamento. Em outros casos, a suposta participação serviria para legitimar as ações do Executivo conforme uma política pouco ou nada democrática. Nesse sentido, destacam-se no âmbito da Política Nacional de Turismo os programas de municipalização e regionalização do turismo, assim como suas estratégias que envolvem a criação de conselhos e outras estruturas de governança.

Nas décadas posteriores aos anos 1990, o planejamento do turismo apresentou a tônica da participação como parte de um modelo de planejamento que possibilitaria a inclusão social. Segundo o Plano Nacional de Turismo 2003/2007: "O turismo quando bem planejado, dentro de um modelo adequado, onde as comunidades participam do processo, possibilita a inclusão dos mais variados agentes sociais". (MTUR, 2003, p. 04). Participação como inclusão, essa concepção do processo participativo, ainda que baseada em princípios democráticos (decisões compartilhadas), ainda não concebe a sociedade como apta a decidir e a realizar, mas como uma parcela beneficiária do próprio planejamento.

Desde a criação do Ministério do Turismo, em 2003, os planos de turismo apresentaram o conceito de participação como inclusão social, sem que inclusão signifique compartilhamento de decisões e construção coletiva das plataformas para o desenvolvimento do turismo, mas inclusão das populações na atividade entendida prioritariamente como geradora de emprego e renda. Assim, é importante refletir criticamente a ideia de participação como inclusão do maior número de agentes na cadeia produtiva do turismo e não a de criação de mecanismos de decisões compartilhadas, construção conjunta de políticas e objetivos para o desenvolvimento do turismo a partir das populações locais e comunidades.

De modo geral, é possível afirmar que os processos decisórios na política de turismo no Brasil são formados por movimentos de "cima para baixo", ainda que seja possível apontar esforços institucionais no sentido da descentralização das diversas esferas de governança. A participação social no turismo está majoritariamente associada ao planejamento e à gestão estatal da atividade, sendo possível vislumbrar um longo caminho para que as ações comunitárias e regionais em prol do turismo possam efetivamente ser construídas a partir da participação, visando o envolvimento e não somente como ação estatal que conta com a sociedade para ser espraiada no território.

\section{PARTICIPAÇÃO SOCIAL, DESENVOLVIMENTO COMUNITÁRIO E PLANEJAMENTO PARTICIPATIVO: CONTRIBUIÇÕES AO PLANEJAMENTO DO TURISMO DE BASE COMUNITÁRIA}

Em um primeiro momento, a ideia de participação se confunde com a de fazer parte de um todo, de compor certa coletividade; e, por isso, o termo, quando excluídas suas nuances contextuais, pode sugerir a ideia de dádiva (MAUSS, 1974). A dádiva como prática social, segundo o autor supracitado, é algo 
que se oferece ao outro em troca do que se recebe. Assim, a participação no sentido de dádiva resultaria de um processo histórico culturalmente marcado por cosmologias e práticas tradicionais. No Brasil, algumas etnias indígenas, assim como outros grupos tradicionais, compartilham desse sentido de troca social.

Já a participação como dádiva, como compromisso social, imprime sentido nos contextos comunitários mais genuínos, onde o grupo cultural convive com um sentimento de falta ou "dívida" com o outro comum. Nesse sentido, há todo um envolvimento e compromisso para que as atividades coletivas aconteçam, assim como uma divisão de tarefas. Em Minas Gerais, a aldeia pataxó Imbiruçu propõe aos visitantes uma espécie de dádiva quando esperam por alguma doação - assim como o compromisso e respeito com a cultura do grupo social -, o que representa uma reciprocidade em relação a tudo que doam gratuitamente durante a Festa das Águas. A Festa, do mesmo modo, é construída a partir do sentido da dádiva, com a participação compartilhada pelos membros comunitários (ALMEIDA, 2015).

$\mathrm{Na}$ atualidade, muitos territórios são chamados de comunidades, no contexto do turismo de base comunitária, sem que haja arranjos sociais e culturais comunitários, ou seja, conformados por relações e organizações comunitárias. Nesse sentido, a discussão acerca da participação social em comunidades deve se dar de modo ampliado, considerando suas nuances e contradições, quando muitas "comunidades" são atravessadas por processos locais e territoriais fortemente vinculados à modernização e urbanização.

Basta refletir um pouco mais sobre o exercício de democracia no contexto brasileiro que, muitas vezes, se resume ao momento do voto, que nos vem a sensação sempre presente de que a falta de opções e a concentração de poder é uma realidade no Brasil. Essa condição acaba por favorecer o entendimento de que o termo participação social ou participação popular é extremamente passível de manipulação. Apesar da situação se apresentar como fato, em muitos casos percebe-se o predomínio da falta de visão crítica por aqueles que se referem à democracia representativa (modelo do estado brasileiro), como se o referido modelo fosse o único regime democrático vigente. Sabe-se que o tipo de regime representativo, oposto ao regime da democracia direta, ao alienar poder decisório em favor de outrem, por meio da representação, impede a participação popular direta - o que favoreceria uma verdadeira participação (SOUZA, 2008). Portanto, é importante salientar, inicialmente, que a participação legítima dos grupos ou cidadãos nos processos de planejamento e gestão no Brasil apresenta dificuldade de realização, pois depende da aplicação de processos autogestionários para reverter a forte tendência à pseudoparticipação ou à não participação. ${ }^{3}$

Se considerarmos o modo como a participação foi conduzida nos processos de planejamento turístico brasileiro, tendo em vista a reflexão inicial deste texto, pode-se perceber uma tendência à pseudoparticipação - que se caracteriza por um modo de manipulação em que os agentes se sentem parte integrante -, mas sem que haja verdadeiro poder de decisão. Os conselhos consultivos de turismo são exemplos marcantes. Por outro lado, quando pensamos nos contextos comunitários, a participação direta pode se tornar mais facilitada em função do tamanho da população envolvida. Entretanto, proximidade nem sempre significa comprometimento comum, e envolvimento direto pode não significar poder de decisão. Nesses casos, será preciso considerar outros fatores que dizem respeito aos conceitos de conquista e autonomia, conceitos que serão tratados no próximo subtítulo deste artigo.

Historicamente, o surgimento da palavra participação está vinculado à ideia da necessidade da participação social. Shiva (2000) afirma que, a partir da década de 1970, o termo participação passou a assumir um caráter de controle social e até de manipulação, uma vez que os projetos de desenvolvimento

3 Marcelo Lopes de Souza (2001), ao considerar a realidade brasileira, apresenta uma proposta de escala de participação que inclui três situações: não participação, pseudoparticipação e participação. 
propostos pelo governo ou por instituições internacionais estabeleciam a noção de participação social como recurso. A origem dessa visão da participação social pode ser atestada na trajetória do conceito de desenvolvimento comunitário (DC).

Conforme Souza (2004), ainda na década de 1950, surgia pela primeira vez a expressão desenvolvimento de comunidade, que teria sido usada pelo governo britânico em 1942, como uma preocupação para manutenção das relações com suas colônias. A partir de um contexto colonialista, portanto, o sentido do DC vai sendo construído e revelado como um processo de intervenção dirigido às comunidades - no sentido de populações locais ou rurais - com o objetivo de melhorar o nível econômico de vida. Já na década de 1960, a ONU incorpora essa expressão e fortalece o sentido do DC como um processo em que o povo participa do desenvolvimento do planejamento e de programas voltados ao crescimento econômico. Nesse momento, busca-se a "colaboração" do povo para aplicação da política de desenvolvimento econômico nas comunidades. Essa visão da ONU é aceita internacionalmente e a Índia é o primeiro país a lançar um programa oficial de DC, em que a unidade de desenvolvimento é a comunidade e esta é estimulada a "participar" no nível da execução dos programas e projetos de desenvolvimento econômico. É aqui que o sentido de "recurso" ganha força, quando a comunidade é chamada a "participar" para facilitar a execução da política internacional.

Nesse sentido, o uso do termo participação em projetos de desenvolvimento e de planejamento se torna um tipo de recurso que favorece o conhecimento do território, uma vez que para implementar a "participação" nos projetos é necessário mobilizar as organizações locais (ONGs e Terceiro Setor) e, ao mesmo tempo, criar redes de relacionamento que facilitem a implantação de novos projetos a partir de ideias originárias de grupos externos à comunidade. As próprias ONGs acabam representando a redução de custos para a implementação de projetos de desenvolvimento, uma vez que os encargos trabalhistas são menores se comparados aos custos de mão de obra pública, sobretudo porque as ONGs são, em geral, marcadas pela informalidade (DAGNINO, 2004). Além disso, favorecem a agilidade nos processos de execução de ações, pois são menos burocratizadas. Em outros casos, as ONGs cumprem um tipo de serviço que se aproxima muito do padrão das empresas de consultoria.

A referência às ONGs e ao terceiro setor como as instituições que, de alguma maneira, representam a sociedade civil (e as comunidades no contexto do turismo de base comunitária) remete a um contexto histórico, no caso do Brasil e também da América Latina, relacionado ao movimento de redemocratização. O envolvimento das ONGs nos processos de desenvolvimento pode ser compreendido a partir de três fases (SHIVA, 2000). A primeira fase é marcada pelo seu surgimento nos acordos de paz pós-2a Guerra e da política desenvolvimentista dos EUA, o que fortalece as iniciativas de DC na década de 1950. Uma segunda fase é definida pelo crescimento do número de organizações não governamentais a partir da política europeia de desenvolvimento dos países africanos e asiáticos; e a terceira e atual fase vincula-se aos processos de globalização e aos agentes financiadores ligados ao capital financeiro internacional.

O envolvimento de ONGs na política de desenvolvimento brasileira culminará com o processo de redemocratização do Brasil, cujo marco é a Constituição de 1988, como vimos. Nesse momento, ampliamse os espaços públicos destinados à suposta participação nos processos decisórios e o controle social das políticas públicas. É inegável que a Constituição cria instrumentos de democracia representativa e democracia direta, tais como plebiscito, referendo, projetos de lei de iniciativa popular, tribunas populares, conselhos e fóruns (DAGNINO, 2004). E mais, a Constituição introduz a questão da participação e da descentralização como exigência para a implementação de políticas públicas e não somente como resultante da pressão popular (grupos e movimentos), adquirindo um tom formal. Apesar dos ganhos da Constituição como marco legal para a aplicação de políticas públicas menos excludentes e conservadoras, 
a exigência da participação, além de adquirir um tom formal, pode resultar em consequências negativas no contexto das causas políticas, pois as instâncias participativas podem ser usadas como manobras para manipulação de grupos de interesse.

A participação, nesses termos, afasta-se do sentido de dádiva, de algo "espontâneo" ou emergente em alguma sociedade ou contexto de resistência, para se aproximar da ideia de ser parte de um projeto predefinido, ou seja, o povo é convidado a "participar" passivamente. Souza (2004) vai mais além e afirma que o propósito do desenvolvimento de comunidade é legitimar a política externa para a manutenção do crescimento econômico e o progresso dos países desenvolvidos, convergindo a ação do desenvolvimento comunitário a uma política global colonialista. Apesar disso, a ONU em 1956 define o desenvolvimento comunitário como um movimento voltado à melhoria de vida das comunidades e com participação ativa, seja através da iniciativa das comunidades ou por meio do uso de técnicas voltadas à animação do movimento. Movimento esse que tinha a ideologia do progresso e do desenvolvimento econômico como paradigma norteador da "ajuda" das comunidades, por meio do aumento da produção e da instalação de estruturas produtivistas.

Desse modo, a intervenção proposta e realizada pelo desenvolvimento comunitário até meados da década de 1960 resultou em profunda mudança cultural no contexto rural e tradicional do mundo "subdesenvolvido", por meio da inserção de técnicas voltadas ao progresso das comunidades. É nesse momento que a cultura do povo é estudada para que intervenções fossem feitas no sentido do desenvolvimento desejado pelos órgãos financiadores da política de desenvolvimento. Uma inaceitável falta de respeito com os valores e crenças tradicionais, o que atesta o caráter dominador e colonialista, vistos por esses mesmos órgãos como fatores dificultadores da aplicação da política internacional. Nesse sentido, percebe-se a influência da filosofia do desenvolvimento comunitário no estabelecimento dos modos de intervenção social e do planejamento nas comunidades. O diagnóstico da cultura, nesses termos, é compreendido como uma etapa necessária à dominação e ao controle social.

Diante do cenário devastador começaram a surgir reações ainda na década de 1960, pois além da política de desenvolvimento comunitário corromper os princípios da participação, por meio de estratégias de manipulação para dominação, estudos sociais apontavam o crescimento contínuo da pobreza nos países "subdesenvolvidos" (SOUZA, 2004), ou seja, a política de desenvolvimento econômico não estava atendendo às necessidades sociais das ditas comunidades. Dessa situação surgiram os primeiros escritos acerca do desenvolvimento social. Nessa direção, há uma primeira ressignificação do conceito de desenvolvimento comunitário, quando passa a ser compreendido como um método de ajuda das comunidades a partir das necessidades sentidas e dos projetos de ação voltados ao aprendizado de atitudes, experiências e processos participativos.

Outras definições apontam para um processo pedagógico de organização social a partir de alguns princípios voltados para a ampliação das escolhas das pessoas e dos lugares: necessidades sentidas, participação, autossustentação e universalidade (SOUZA, 2004). No Brasil, destaca-se a emergência da pesquisa-ação, dos diagnósticos rápidos participativos no meio rural (DRP), que emergem como uma reação à lógica da intervenção colonialista e produtivista no campo. Apesar dos "avanços" decorrentes da reação contra a visão de "progresso" das comunidades e a inclusão de aparente autonomia dos grupos comunitários no processo de desenvolvimento, o caráter de ajuda às comunidades permanece.

Já no século XXI, no âmbito da política pública de turismo, podemos citar programas de turismo de base comunitária e ou solidária que explicitam esse sentido. Em Minas Gerais, o Programa Turismo 
Solidário é exemplar. Segundo informações do site oficial do programa ${ }^{4}$, ele foi idealizado para levar melhores condições de vida (oportunidades de emprego e renda) ao norte e nordeste do estado de Minas Gerais. É importante que, nesse caso, estamos nos referindo a um território considerado pobre pelo imaginário social em função de um histórico de marginalização bem particular. Ao contrário do que deveria, o estereótipo social é reforçado pela política quando propõe um turismo solidário sem que haja, concomitantemente, um processo de mobilização e empoderamento social, entre outros fatores. A ajuda substitui o direito de escolha e de articulação para a transformação desejada. Além disso, a política reforça a ideia de dependência das comunidades em relação aos agentes de desenvolvimento e aos turistas. Outro ponto a salientar é que o programa adota os mesmos recursos, critérios e práticas para toda uma região sem considerar as particularidades de cada território ou comunidade.

O sentido de auxílio, de ajuda, é uma característica ainda muito utilizada na intervenção comunitária e que esconde um importante paradoxo dos processos participativos. Esse é um ponto central para a discussão conceitual do sentido da participação social no planejamento do turismo de base comunitária. O caráter de "ajuda" da intervenção comunitária, tradicionalmente presente nos estudos da psicologia social comunitária, parte do pressuposto de que essas comunidades são carentes e pobres, e precisam do serviço de um profissional para "salvá-las". Essa é uma visão preconceituosa, pois parte de antemão que essas comunidades são comunidades com problemas (GUARESCHI, 1998). Não poderia ser o caso de encontrar comunidades com alto grau de participação e grande coesão afetiva, com grande capacidade de realização e autogestão? Aliás, as "verdadeiras" comunidades se constituem pela capacidade de luta coletiva e participação como exercício de autogestão, pois é em torno das dificuldades compartilhadas que os vínculos de proximidade (BARTHOLO, 2009) e dever social (ESPÓSITO, 2010) são constantemente firmados.

Portanto, está revelado o sentido da participação social: a participação não é algo natural, dado, ensinado ou recebido; a participação é conquista (DEMO, 1988)! Participação requer consciência e luta, conquista coletiva em torno da autopromoção dos grupos de resistência que reivindicam melhores condições de vida. A participação social será sempre um processo que envolve a consciência estratégica dos grupos sociais em torno do fortalecimento de identidades coletivas. Esse processo, por outro lado, é constituinte de referências comuns compartilhadas que sustentarão as relações comunitárias e os processos autogestionários.

Pode-se dizer que uma comunidade se constrói nas relações de proximidade (BARTHOLO, 2009) e nas relações comunitárias (GUARESCHI, 1998), laços que estabelecem vínculos e compromissos comuns. As relações comunitárias são definidas "por uma participação profunda dos membros do grupo, onde são colocadas em comum relações primárias, como o próprio ser, a própria vida, o conhecimento mútuo, a amizade, os sentimentos" (GUARESCHI, 1998, p. 95). Essa visão de comunidade e participação, no entanto, nem sempre corresponde às referências dos agentes de desenvolvimento e planejamento. Aliás, todo tipo de planejamento é, de algum modo, impositivo (DEMO, 1988). A própria natureza da intervenção social nasce da ideia da ação iniciada pelos agentes externos. Essa situação contribui para que a intervenção social por meio do planejamento adquira um caráter autoritário ou tutelar, em muitos casos, ao subestimar as capacidades humanas comunitárias, ao ignorar os saberes e as práticas coletivas construídas ao longo da história dos territórios tradicionais e comunitários.

Como vimos, participação - segundo o processo de modernização da gestão estatal - não seria exatamente uma conquista da sociedade civil autônoma e envolvida na construção das políticas e processos

4 http://www.turismosolidario.com.br/ 
decisórios, mas um processo de transferência à sociedade civil de funções públicas anteriormente atribuídas ao Estado, de modo que a referida arcaria com parte dos custos e das responsabilidades.

Diferente da visão do planejamento administrativo ou estatal, o planejamento participativo pode ser compreendido por duas correntes teóricas: pela teoria das políticas urbanas e das políticas sociais. Se pensarmos do ponto de vista da teoria do planejamento urbano, o planejamento participativo se insere, inicialmente, como abordagem do planejamento e gestão urbanos críticos vistos de uma perspectiva autonomista. Souza (2008) localiza a filosofia política de Cornelius Castoriadis como principal inspiração para um olhar alternativo e não usual ao planejamento. A principal contribuição desse filósofo se refere à proposta de "refundação" da democracia a partir do que chamou de projeto de autonomia.

A autonomia como princípio filosófico para Castoriadis, entretanto, adquire dois sentidos que são inter-relacionados e complementares nos processos de planejamento e gestão: a autonomia coletiva e a autonomia individual. A autonomia coletiva imprime significado ao autogoverno de uma determinada coletividade, e a autonomia individual, por outro lado, se refere à capacidade dos indivíduos de realizarem escolhas em liberdade, com responsabilidade e conhecimento de causa. Ambas, juntas, permitiriam a prática de processos que seriam alternativas ao projeto de planejamento global. Essas bases seriam definidoras do surgimento de uma sociedade autônoma, ao contrário do que se pratica no Brasil, uma sociedade predominantemente heterônima.

A sociedade autônoma fornece fundamentos relevantes para a defesa de mecanismos e instituições facilitadores de processos integradores, capazes de permitir aos cidadãos a construção de um projeto de desenvolvimento alternativo, a partir das necessidades e percepções particulares e legítimas dos diferentes grupos e comunidades. Isso não significa, entretanto, que se esteja pensando em uma abordagem ingênua da sociedade atual. Pensar possibilidades de autonomia não significa propor o retorno da pólis grega e, tampouco, a desconsideração da complexidade contemporânea.

Vimos que a inserção da participação de modo mais aplicado nas políticas públicas de turismo no Brasil se deu a partir de meados da década de 1990. Entretanto, quando pensamos na presença de instrumentos de uma política pública de turismo no contexto comunitário, é necessário dizer que ainda há muito a se fazer, já que apenas no ano de 2008 foi anunciada publicamente uma ação formal - Edital 01/2008 do Ministério do Turismo - voltada ao financiamento de iniciativas de turismo de base comunitária (BARTHOLO, SANSOLO, BURSZTYN, 2009). Diante da crítica às políticas hegemônicas no campo do turismo, surge uma articulação de pesquisadores, técnicos e estudiosos em torno da conceitualização e normatização do turismo de base comunitária.

Apesar dos esforços recentes - demonstrados em novas publicações que abrangem áreas como o contexto Amazônico (NOVO; CRUZ, 2014), para além do já conhecido contexto nordestino em que se localizam os primeiros movimentos de turismo comunitário no Brasil -, quando se pensa no contexto comunitário brasileiro verifica-se pelo menos uma forte tendência: a presença relativa de autonomia coletiva, principalmente em comunidades caracterizadas por históricos de resistência e ou por culturas tradicionais.

Já a autonomia individual é mais complexa em contextos tradicionais, em que a tradição como cultura inventada acaba por exercer forte poder sobre as identidades individuais (ALMEIDA, 2017). Essa é uma questão central que deveria ser enfrentada caso haja intenção compartilhada de planejamento participativo no contexto comunitário: a participação ampliada dos sujeitos comunitários. No sentido comunitário, a participação individual ganha grande importância, pois pode minimizar certas distorções e legitimações de poder, tanto em relação à propensão impositiva dos técnicos herdada do planejamento tecnocrático 
(DEMO, 1988) quanto em relação à manutenção forçada de certas estruturas ou valores tradicionais. Além disso, a participação ampliada favorece a construção de responsabilidades compartilhadas entre os diferentes sujeitos e grupos comunitários. Por outro lado, se sabe que onde existe autogestão existe autoplanejamento, e isso já imprime um caráter amplo de autonomia comunitária que significa a não necessidade da intervenção social ou do planejamento. As parcerias com outros autores se dariam de outros modos, de igual para igual, onde os comunitários apresentariam suas demandas ao Estado e aos demais atores.

Nesse sentido, ateoria social concebeo planejamento participativo como umaforma deantiplanejamento, pois aposta em mudanças favoráveis aos desiguais, mesmo que estas tenham um caráter reformista. Três são os componentes básicos do planejamento participativo como política social (DEMO, 1988). O primeiro se refere ao processo inicial de formação da consciência crítica e autocrítica na comunidade, por meio do qual se constrói a consciência coletiva e individual acerca da condição social que afeta a comunidade, principalmente em relação aos problemas de injustiça social, se for o caso. Esse processo pode ser chamado de autodiagnóstico, "quando a comunidade formula com o seu saber técnico um posicionamento crítico em relação à realidade" (DEMO, 1988, p. 45). O segundo, por sua vez, diz respeito ao enfrentamento dos problemas autodiagnosticados por meio da construção de um autoprognóstico de ações prioritárias e de caminhos alternativos que envolvam propostas de negociação com os diferentes atores envolvidos. Já o terceiro, finalmente, diz respeito à necessidade de auto-organização como estratégia fundamental para alcance da mudança desejada. Esse ponto é visto como um teste em relação à capacidade de autonomia dos grupos ante os compromissos democráticos assumidos com a escolha do planejamento participativo.

$\mathrm{Na}$ realidade, verifica-se a convergência nas concepções apresentadas, já que a diferença entre o planejamento participativo e o planejamento convencional se refere à incorporação da abordagem autônoma em relação às clássicas etapas: diagnóstico, prognóstico e organização/gestão. Desse modo, o planejamento participativo se apoia no saber técnico das comunidades, ou seja, se sustenta do conhecimento herdado e criado em torno dos modos particulares de viver e produzir de cada território comunitário. Saber cultural, saber ambiental, saber comunitário, saber-fazer por si mesmos que permite a sobrevivência de grupos que partilham territórios e vidas comuns.

Os saberes referidos acima são os conhecimentos-saberes que permitem a construção de relações comunitárias. Portanto, os saberes turísticos construídos pelas comunidades seriam uma espécie de desdobramentos dos próprios saberes comuns, tradicionais e comunitários. Há muito mais para se aprender nas "verdadeiras" comunidades do que a se ensinar. No entanto, é preciso dizer que o saber comunitário é uma raridade no mundo ocidental - até mesmo nas ditas comunidades tradicionais -, pois, como se sabe, comunidade é uma palavra já muitíssimo desgastada e isso se deu, sobretudo, à própria ausência de comunidade e de práticas comunitárias em mundos nomeados como comunidades.

A revelação desses sentidos engendra fortes desafios para os agentes de desenvolvimento, bacharéis e profissionais do planejamento comprometidos com o turismo de base comunitária. Afinal, os pressupostos do turismo de base comunitária, de acordo com a Rede Brasileira de Turismo Solidário e Comunitário (Turisol), incorporam o compromisso com o atendimento das necessidades dos comunitários, com a autogestão, a participação e a justiça socioambiental. Isso significa a necessidade de enfrentamento de algumas questões centrais: Será que as universidades e demais instituições educacionais oferecem uma formação capaz de formar planejadores críticos e autocríticos em relação à sua própria atuação nas comunidades? Será que os estudantes estão dispostos a assumir a posição de agentes mobilizadores e assessores das comunidades, em substituição à posição de detentores do conhecimento técnico?

Por outro lado, considerando o histórico do desenvolvimento comunitário e do planejamento no Brasil, 
será que as chamadas comunidades - aquelas que são chamadas de comunidade por serem pequenos grupos locais ou rurais, mas que apresentam relações e arranjos individualizados - estão dispostas a enfrentar a sua realidade, no sentido de romper com a tendência racionalista, assistencialista e tutelar dos projetos de desenvolvimento no Brasil para construírem projetos autônomos de desenvolvimento e de turismo? Como favorecer a mudança da postura de recebimento de favores para a postura de luta a favor dos direitos e da solução de seus próprios problemas? De que modo o turismo de base comunitária como política alternativa de desenvolvimento do turismo assume, de fato, o compromisso com o planejamento participativo do turismo e a autonomia nos contextos comunitários?

Esses e outros questionamentos são apresentados para suscitar a reflexão diante da ausência de comprometimento do Estado com os grupos culturais tradicionais e comunidades. Trata-se de um exercício de autocrítica, tendo em vista a proliferação de projetos de turismo de base comunitária no Brasil a partir dos anos 2000, que parecem mais substituir o turismo de base local do que significar, definitivamente, uma resposta alternativa aos projetos globais e hegemônicos. A questão-problema a se enfrentar não parece estar na escala do território, mas nos diversos âmbitos que envolvem as relações comunitárias e não comunitárias.

\section{CONSIDERAÇÕES FINAIS}

As reflexões acima suscitam alguns desdobramentos teóricos ante os desafios da intervenção crítica e comprometida com a justiça social nos contextos comunitários. Nesse sentido, as ações vinculadas aos projetos de turismo de base comunitária merecem grande atenção, pois lidam diretamente com a construção de expectativas e com o futuro dos grupos sociais. Este artigo enfrentou a questão do planejamento participativo no contexto comunitário como uma estratégia para se pensar os modos de intervenção do turismo de base comunitária no Brasil e o seu compromisso com os sentidos da participação social. O que se conclui é que a política pública de turismo no Brasil não legitima os sentidos genuínos da participação social no contexto do planejamento e da gestão do desenvolvimento e do turismo. Nesse sentido, ignoram a potência de transformação do turismo de base comunitária como um paradigma alternativo ao turismo convencional; um modo de se pensar o turismo a partir do saber técnico das próprias comunidades, um modo de pensar o turismo a partir das cosmologias particulares a cada comunidade.

Para que haja um real compromisso com o Turismo de Base Comunitária (TBC), é essencial que os sentidos do planejamento participativo, pautados na autonomia e na autocrítica das comunidades, sejam incorporados pelos princípios reguladores de TBC, assim como pela desejada política pública de turismo de base comunitária, ainda inexistente no Brasil, já que o histórico brasileiro revela apenas um programa temporário de TBC, ao contrário do que seria uma política pública. Nesse sentido, gostaríamos de terminar essa breve reflexão chamando atenção para alguns aspectos que fortalecem a ideia de que as comunidades são entidades que possuem um "saber" próprio, que, em geral, é diferente do saber moderno ocidental.

Esse conhecimento abundante de sabedoria merece, no mínimo, que duas ações façam parte das agendas dos planejadores do TBC. A primeira: a garantia ao respeito e à incorporação do saber comunitário em todas as intervenções em prol do planejamento do turismo de base comunitária, desde o seu início. Isso exige um olhar humilde, crítico e cuidadoso dos próprios agentes planejadores em relação à sua postura quase sempre impositiva. A segunda: que todos os projetos de TBC incluam, além do diálogo e a partilha 
de saberes, a garantia da autonomia coletiva e individual e a autogestão das próprias comunidades. Isso significa que será necessária a reivindicação da construção de uma política pública de turismo de base comunitária com respeito a esses princípios e que supere os valores condicionados pela política pública de turismo, a saber: o crescimento econômico e o fortalecimento das iniciativas convencionais existentes.

\section{REFERENCIAS}

ALMEIDA, F. A. B. Viagem, experiência comunitária e desenvolvimento tradicional na aldeia pataxó Imbiruçu. Painel apresentado no Encontro Nacional Turisol - Rede Brasileira de Turismo Solidário e Comunitário. Brasília: Centro de Excelência em Turismo. Universidade de Brasília, 14 de agosto de 2015.

. Viagens. Belo Horizonte: Instituto de Geociências, Universidade Federal de Minas Gerais, 2017. Tese de Doutorado.

BARTHOLO, R. O sentido de proximidade: implicações para um turismo situado de base comunitária. In: BARTHOLO, R.; SANSOLO, D.; BURSZTYN, I.; (Org.). Rio de Janeiro, Letra e Imagem, 2009.

BARTHOLO, R.; SANSOLO, D.; BURSZTYN, I. (Org.). Turismo de base comunitária: diversidade de olhares e experiências brasileiras. Rio de Janeiro, Letra e Imagem, 2009.

BRASIL. Ministério do Turismo. Plano Nacional de Turismo. Diretrizes, Metas e Programas. 20032007. Brasília: Ministério do Turismo, 2003. Disponível em: 〈http://www.turismo.gov.br/images/ pdf/plano_nacional_2013.pdf.>. Acesso em: 02 ago. 2017.

CRUZ, R. de C. Política de turismo e território. 2. ed. São Paulo: Contexto, 2001.

DAGNINO, E. “¿Sociedade civil, participação e cidadania: de que estamos falando?” In: MATO, D. (Coord.). Políticas de ciudadanía y sociedad civil en tiempos de globalización. Caracas: FACES, Universidad Central de Venezuela, p. 95-110. 2004.

DEMO, P. Participação e conquista. São Paulo: Cortez: Autores Associados, 1988.

ESCOBAR, A. Planejamento. In: SACHS, W. Dicionário do desenvolvimento: guia para o conhecimento como poder. Petrópolis: Vozes, 2000. p. 211-228.

ESPÓSITO, R. Communitas: the origin and destiny of community. Tradução de Timothy Campbell. Califórnia: Stanford University Press, 2010.

ESTEVA, G. Desenvolvimento. In: SACHS, W. (Ed.). Dicionário do Desenvolvimento. Petrópolis: Vozes, 2000, p. 59-83.

GUARESCHI, P. A. Relações comunitárias: relações de dominação. In: CAMPOS, R. H. de F. (Org.). Psicologia social comunitária: da solidariedade à autonomia. 13. ed. Petrópolis: Vozes, 1998.

HISSA, C. E. V. Entrenotas: compreensões de pesquisa. Belo Horizonte: Editora UFMG, 2013.

MAUSS, M. Ensaio sobre a dá-diva. Forma e razão da troca nas sociedades arcaicas. In: Sociologia e Antropologia. v. II. São Paulo: Edusp. 1974 [1923-24].

NECHAR, M.; NETTO, A. Epistemología del Turismo: estúdios críticos. México: Trillas, 2010. 
NOVO, C.; CRUZ, J. (Org.). Turismo comunitário: reflexões no contexto Amazônico. Manaus: Edua, 2014 .

SANTOS, B. de S. Um discurso sobre as ciências. 7. ed. São Paulo: Cortez, 2010.

SHIVA, V. In: SACHS, W. Dicionário do desenvolvimento: guia para o conhecimento como poder. Petrópolis: Vozes, 2000. p. 300-316.

SOUZA, M. L. de. Mudar a cidade: uma introdução crítica ao planejamento e à gestão urbanos. 5. ed. Rio de Janeiro: Bertrand Brasil, 2008.560 p.

SOUZA, M. L. de. Desenvolvimento de comunidade e participação. 8. ed. São Paulo: Cortez, 2004. 